\title{
THE RICHARD'S MASCULINITY IN FILM LOVE FOR SALE 1
}

\author{
Reza Chandra Ramadhana ${ }^{1}$ dan Citra Dewi Utami ${ }^{2}$ \\ ${ }^{1}$ Institut Seni Indonesia (ISI) Surakarta, Indonesia \\ 2 Institut Seni Indonesia (ISI) Surakarta, Indonesia \\ E-mail: rezachandra52@windowslive.com
}

\begin{abstract}
This research focuses on the masculinity of a male character named Richard Achmad in the film Love for Sale 1 directed by Andibachtiar Yusuf. The purpose of this study was to determine the social construction of men depicted in the masculinity of Richard's character. This type of research is qualitative research with the technique of collecting Saturated Sampling data. Observation and Literature Study method as a data collection method. Data analysis uses Interactive Data Analysis including data reduction, data display and conclusion drawing / verification. The reading of John Beynon's masculinity is used as an approach to find the masculinity in Richard's character. The results showed that the male social construction built in the film Love for Sale 1 is a representative of the social construction picture that exists in real life. There are similarities in the social construction of masculinity between Richard's character in the film Love for Sale 1 and in real life.
\end{abstract}

Keywords: Masculinity, gender, and social construction

\begin{abstract}
ABSTRAK
Penelitian ini fokus pada maskulinitas tokoh laki-laki bernama Richard Achmad di film Love for Sale 1 yang disutradarai oleh Andibachtiar Yusuf. Tujuan penelitian ini untuk mengetahui konstruksi sosial laki-laki yang tergambar pada maskulinitas tokoh Richard. Jenis penelitian yang digunakan adalah penelitian kualitatif dengan teknik pengumpulan data Sampling Jenuh. Analisis data menggunakan analisis data interaktif meliputi data reduction, data display dan conclusion drawing/verification. Pembacaan maskulinitas John Beynon digunakan sebagai pendekatan untuk menemukan maskulinitas dalam tokoh Richard. Hasil penelitian menunjukkan bahwa konstruksi sosial laki-laki yang dibangun dalam film Love for Sale 1 merupakan perwakilan dari gambaran konstruksi sosial yang ada di kehidupan nyata. Adanya kesamaan konstruksi sosial maskulinitas antara tokoh Richard dalam film Love for Sale 1 dengan di kehidupan nyata.
\end{abstract}

Kata kunci: Maskulinitas, gender, dan konstruksi social.

\section{PENDAHULUAN}

Film adalah salah satu media komunikasi yang memiliki banyak makna yang tersembunyi dalam narasinya. Oleh karena itu diperlukan analisis naratif dalam menganalisis narasi dalam sebuah film. Pesan-pesan yang dimiliki suatu film diangkat berdasarkan gagasan dari sutradara dalam pembuatan alur dan cerita yang berbentuk narasi (Wulan Sari \& Haryono, 2018).

Kekuatan dan kemampuan film menjangkau banyak segmen sosial, membuat film memiliki potensi untuk mempengaruhi khalayaknya. Sejak itu, maka berkembang berbagai penelitian yang 


\section{CAPTIRE}

hendak melihat dampak film terhadap masyarakat. Sejumlah penelitian film mengambil berbagai topik terkait seperti: pengaruh film terhadap anak, film dan agresivitas, film dan politik, dan seterusnya (Sobur, 2009). Lebih jauh, Irawanto (dalam Sobur, 2009) mengatakan bahwa kritik yang muncul terhadap perspektif ini didasarkan atas argumen bahwa film adalah potret dari masyarakat di mana film itu dibuat. Film selalu merekam realitas yang tumbuh dan berkembang dalam masyarakat, dan kemudian memproyeksikannya ke atas layar.

Film Love for Sale 1 merupakan film drama romantis yang sutradarai oleh Andi Bachtiar Yusuf, bercerita tentang kisah hidup seorang laki-laki bernama Richard, masih betah melajang padahal usia telah menginjak 41 tahun. Richard mempunyai hidup yang membosankan setiap harinya, karena Richard sangat menikmati hidup seorang diri dibanding menelusuri dunia luar. Richard mempunyai bisnis percetakan yang diwarisi dari keluarga angkatnya dan hal itu membuat Richard memiliki watak tegas, emosional, dan disiplin.

Tetapi, kehidupan Richard berubah setelah Richard bertemu dengan seorang wanita bernama Arini Kusuma. Richard mengenalnya melalui sebuah aplikasi startup bernama Love Inc. Setelah bertemu Arini, keseharian Richard mulai bermakna karena merasa disayangi oleh Arini. Hal itu membuat watak Richard yang tegas dan emosional menjadi sosok yang perhatian dan lemah lembut. Richard pun jatuh cinta kepada Arini. Akan tetapi, Arini kemudian pergi meninggalkan Richard tanpa alasan. Akhirnya, Richard memilih pergi dari tempat tinggalnya berkelana seorang diri.

Penggambaran maskulinitas dan feminitas pada film drama romantis tergambar sangat jelas. Hal itu berguna untuk mengidentifikasi konstruksi sosial karakter laki-laki dan karakter perempuan dalam film. Dengan demikian, pemilihan film drama romantis untuk mengkaji maskulinitas sangat tepat, karena film drama romantis sangat erat dengan hubungan antara laki-laki dan perempuan seperti yang tergambar pada film Love for Sale 1. Laki-laki dan perempuan memang termasuk dalam objek yang dikaji. Karenanya, kita baik sebagai laki-laki maupun perempuan sudah membentuk struktur-struktur historis tatanan maskulin dalam bentuk beberapa skema tak sadar yang mengatur persepsi dan apresiasi kita (Bourdieu, 2010).

Penggambaran maskulinitas pada tokoh Richard menarik untuk dibahas. Hal itu bertujuan untuk mengetahui karakter maskulin yang dibentuk oleh sutradara pada tokoh Richard sebagai penggambaran bentuk konstruksi sosial laki-laki pada film Love for Sale 1. Pencitraan diri maskulinitas laki-laki juga dapat dilihat dari kehidupan sehari-hari yaitu cara berpakaian dan penampilannya, aksesoris yang dikenakan, 
cara menyelesaikan permasalahannya, aktivitas, cara bergaul, serta ekspresi verbal dan nonverbal. Selain itu, adanya doktrindoktrin pembentukan karakter maskulin yang tidak tertulis, tetapi telah diwariskan secara turun-temurun melalui budaya, seperti misalnya laki-laki sejati tidak boleh menangis, harus terlihat kuat, berani, berotot, macho, gentle, dan sebagainya. Walaupun bersifat tidak pasti, namun bentuk maskulinitas sering diperlihatkan dalam film. misalnya sosok laki-laki mendominasi laki-laki lain, baik dari kriteria fisik, cara bersikap, maupun segala aspek pandukung yang ada di sekitarnya. Salah satu indikator yang paling sering diperlihatkan yaitu seorang laki-laki dikatakan maskulin adalah dengan adanya sosok perempuan.

Penelitian ini fokus mengkaji maskulinitas karakter Richard yang dapat menggambarkan konstruksi sosial kaum laki-laki dalam film Love for Sale 1.

\section{TINJAUAN PUSTAKA}

Tinjauan teoritik dilakukan melalui beberapa buku yang membahas tentang gender, pengkarakteran tokoh, dan stuktur film.

\subsection{Gender}

Konsep gender adalah suatu sifat yang melekat pada kaum laki-laki ataupun perempuan yang dikonstruksi secara sosial dan kultural, misalnya perempuan itu dikenal lemah lembut, cantik, emosional, atau keibuan, sedangkan laki-laki dianggap kuat, rasional jantan, dan perkasa. Ciri dari sifat itu merupakan sifat-sifat yang dapat dipertukarkan (Bourdieu, 2010). Maskulinitas dan femininitas menjadi suatu nilai yang bergerak dalam tataran sosial, misalnya perempuan selalu identik dengan pekerjaan domestik dan lelaki identik dengan pekerjaan non-domestik. Sandra Bartky (dalam Mecca, 2019) mengatakan bahwa femininitas adalah praktik-praktik yang menghasilkan tubuh perempuan berada dalam sikap dan perilaku yang dianggap feminin.

\subsection{Maskulinitas}

Demartoto (dalam Syulhajji S., 2017), istilah maskulinitas merupakan sebuah konsep yang hadir, karena adanya konstruksi sosial terhadap laki- laki. Lakilaki merupakan sosok yang identik dengan kekerasan, aktif, agresif, logis, ambisius, dan kuat. Kontruksi ini pula yang menyebabkan ketika anak laki-laki lahir sudah dibebankan beberapa hal, seperti norma, kewajiban, dan harapan dari keluarga. Hal ini diturunkan dari generasi ke generasi sehingga seorang laki-laki harus melakukan hal yang telah berlaku, bila ingin menjadi lelaki sejati.

Tabel 1. Karakteristik maskulinitas dan femininitas menurut beberapa ahli

(Sumber: Sparrow, J., and Rigg, C., 1994)

\begin{tabular}{|c|ll|ll|}
\hline & \multicolumn{2}{|c|}{ Maskulinitas } & \multicolumn{2}{|c|}{ Femininitas } \\
\hline \multirow{4}{*}{ Capra } & $\circ$ Banyak & $\circ$ & Responsif \\
& \multicolumn{1}{|c}{ tuntutan } & $\circ$ & Intuitif \\
& $\circ$ Agresif & $\circ$ & Kooperatif \\
& $\circ$ & Kompetitif & $\circ$ & Netral atau \\
\hline
\end{tabular}




\begin{tabular}{|c|c|c|}
\hline & & $\begin{array}{ll} & \text { seimbang } \\
\circ & \text { Mempersatuka } \\
\mathrm{n}\end{array}$ \\
\hline $\begin{array}{l}\text { Boydell \& } \\
\text { Hammond }\end{array}$ & $\begin{array}{ll}\circ & \text { Berfikir logis } \\
\circ & \text { Pisah dari } \\
& \text { sifat alami } \\
\circ & \text { Mekanis } \\
\circ & \text { Otak kiri } \\
\circ & \text { Bersifat } \\
\text { dominan } \\
\circ & \text { Pemisah } \\
\circ & \text { Keras } \\
\circ & \text { Menang- } \\
& \text { Kalah } \\
\circ & \text { Berentetan } \\
\circ & \text { Mengontrol }\end{array}$ & $\begin{array}{l}\circ \text { Tidak logis } \\
\circ \text { Bagian dari } \\
\text { sifat alami } \\
\text { Sistematis } \\
\circ \text { Otak kanan } \\
\circ \text { Bersifat patuh } \\
\circ \text { Penyatu } \\
\circ \text { Lunak } \\
\circ \text { Menang- } \\
\text { Menang } \\
\circ \text { Berjarak } \\
\circ \text { Membebaskan }\end{array}$ \\
\hline
\end{tabular}

John Beynon (dalam Pramudika, 2015), seorang pakar yang meneliti maskulinitas dalam kebudayaan populer mengkategorikan aspek-aspek pembacaan maskulinitas. Berikut merupakan skema pembacaan maskulinitas menurut John Beynon (dalam Pramudika, 2015):

a. Age and Physique : citra fisik diri terbentuk dan berkaitan dengan penampilan fisik, daya tariknya dan kesesuaian dengan jenis kelaminnya dan pentingnya berbagai bagian tubuh untuk perilaku dan harga diri seseorang di mata orang lain.

b. Education : pencitraan laki-laki yang mampu membuat timbulnya ketertarikan orang lain melalui kecerdasan dan status pendidikan.

c. Ethnicity : seseorang mampu memahami pola-pola sosial melalui perilaku yang biasanya digunakan sebagai sebuah ekspresi dari persepsi diri yang positif, dan memberikan manfaat bagi orang lain. d. Geographical : sesorang yang dinilai memiliki pencitraan lebih baik daripada orang lain melalui lingkup lingkungan yang mengelilinginya.

e. Sexual Orientation : pria memiliki pola ketertarikan emosional dan romantis terhadap lawan jenis. Orientasi seksual juga dapat dikatakan sebagai perasaan seseorang terhadap identitas pribadi dan sosial berdasarkan ketertarikan.

f. Class and Occupation : seseorang yang memiliki kapasitas dan kelas dalam setiap aktivitas kegiatan ataupun pekerjaan.

g. Status and Lifestyle : gaya hidup adalah perilaku seseorang yang ditunjukkan dalam aktivitas, minat dan opini khususnya yang berkaitan dengan citra diri untuk merefleksikan status sosialnya. Gaya hidup adalah hal yang paling berpengaruh pada sikap dan perilaku seseorang dalam hubungannya dengan tiga hal utama dalam kehidupan yaitu pekerjaan, persahabatan, dan cinta.

h. Historical Location : laki-laki yang tersubordinasi berdasarkan sejarah yang berhubungan dengan terbentuknya karakter seseorang.

i. Religion and Beliefs : laki-laki yang dinilai melalui kepercayaan dan prinsip yang diyakini terhadap pilihan yang telah ditetapkan.

j. Culture and Subculture : maskulinitas laki-laki yang terbentuk oleh budaya yang ada di sektarnya. 


\subsection{Pengkarakteran}

Setiap film cerita umumnya memiliki karakter utama dan pendukung. Karakter utama adalah motivator yang menjalankan alur cerita baratif sejak awal film hingga akhir cerita. Tokoh utama sering diistilahkan pihak protagonist, sedangkan karakter pendukung bisa berada pada pihak protagonis maupun pihak antagonis (Pratista, 2008).

Karakter utama dibagi menjadi dua kategori, yakni :

\section{a. Protagonis}

Tokoh protagonis merupakan tokoh yang pokok dalam cerita. Tokoh protagonis mewakili hal-hal yang baik dalam cerita. Biasanya tokoh ini merupakan tokoh yang menderita, yang berjuang untuk membela suatu kebenaran, sehingga menimbulkan simpati pada penonton.

\section{b. Antagonis}

Tokoh yang mewakili hal-hal yang negatif dalam cerita. Peran ini merupakan musuh protagonis, tokoh ini biasanya menyakiti dan membuat menderita protagonis, dan tokoh yang menghalangi upaya tokoh protagonis mencapai tujuannya.

Selain itu, tipologi tokoh pada film juga mempengaruhi karakter yang muncul dalam film. Tipologi tokoh adalah istilah psikologis untuk membedakan manusia berdasarkan beberapa tipe agar lebih sederhana. Tipologi tokoh ini dibedakan menjadi dua, yaitu tipe fisik dan tipe psikis
(Lutters, 2004).

a. Tipologi tipe fisik

Tipe ini disebut penggolongan tipe manusia berdasarkan bentuk tubuh, berdasarkan teori E. Kretschmer. Tipologi Kretschmer (dalam Lutters, 2004) ada 4 tipe, yaitu :

1) Piknis

Tipe piknis mengarah pada ciri tubuh pendek dan gemuk (berat badan melebihi berat normal). Jenis tubuh ini banyak lemak sehigga tulang-tulang tidak terlihat. Kegemaran tipe piknis adalah senang makan dan tidur. Tipe piknis sering dikaitkan dengan tipe psikis sanguinis, sehingga cocok untuk seorang penghibur, lucu dan konyol. Orang tipe ini sering dijadikan maskot komedinya.

2) Leptosom

Tipe leptosom mengarah pada tubuh tinggi dan kurus (berat badan kurang dari normal), wajahnya memelas atau sedih. Kegemaran tipe ini membaca buku, menyendiri, dan melamun. Tipe ini sering dikaitkan dengan tipe psikis melankolis, sering menjadi tokoh disakiti dan menderita, dan sering meneteskan air mata. Di dalam komedi, tipe leptosom sering dipasangkan dengan piknis.

3) Atletis

Tipe atletis mengarah pada bentuk tubuh yang tinggi dan kekar, tidak banyak lemak, tapi tidak juga tampak tulang- 


\section{CAPTIRE}

tulang di tubuhnya. Urat-uratnya yang tampak lebih menonjol. Biasanya badannya tegap dan kuat. Perbandingan tinggi dan berat badan seimbang.

4) Displatis

Tipe displatis adalah tubuh yang khas atau tidak umum. Kategori ini tidak dapat dijabarkan dengan detail tertentu, mengingat tipe ini menyimpang dari konstitusi normal, atau disebut spesifik.

b. Tipologi tipe psikis

Tipologi ini bisa dikatakan dengan penggolongan manusia berdasarkan tempramen atau karakter. Di dalam ilmu psikologi, tempramen dan karakter dibedakan. Tempramen adalah bawaan lahir, sementara karakter itu bisa dibentuk. Tipologi psikis dibedakan menjadi empat (Lutters, 2004), yaitu:

1) Sanguinis

Sifat dasar periang, ramah, suka tertawa atau gembira, dan mudah berganti haluan.

2) Melankolis

Sifat dasar: pemurung, penuh anganangan, muram, pesimistis, mudah kecewa, daya juang kurang, bila mengerjakan sesuatu mesti dipikir dengan matang.

3) Koleris

Sifat dasar: hidup keras, bersemangat, daya juang besar, optimis, hatinya mudah terbakar atau terpengaruh, mudah marah, dan kasar.

4) Flagmentis
Sifat dasar: tidak suka buru-buru, kalem, tenang, tidak mudah terbakar dan terpengaruh, mudah marah, dan kasar.

\subsection{Struktur dalam Film}

Film jenis apapun, panjang atau pendek, memiliki struktur fisik. Secara fisik sebuah film dapat dipecah menjadi unsurunsur (Pratista, 2008), yakni :

a. Shot

Shot selama produksi film memiliki arti proses perekaman gambar sejak kamera diaktifkan hingga kamera dihentikan atau juga sering diistilahkan satu kali take (pengambilan gambar). Sementara shot setelah film telah jadi (pascaproduksi) memiliki arti satu rangkaian gambar utuh yang tidak terinterupsi oleh potongan gambar (editing).

b. Adegan (Scene)

Adegan (scene) adalah satu segmen pendek dari keseluruhan cerita yang memperlihatkan satu berkesinambungan yang diikat oleh ruang, waktu, isi (cerita), tema, kerakter, atau motif.

c. Sekuen (Sequence)

Sekuen adalah satu segmen besar yang memperlihatkan satu rangkaian peristiwa penuh. Satu sekuen umumnya terdiri dari beberapa adegan yang saling berhubungan.

\section{METODE}

Penelitian ini menggunakan jenis penelitian kualitatif dengan fokus pada karakter tokoh dalam film Love for Sale 1. 
Metode penelitian kualitiatif berlandaskan pada filsafat postpositivisme atau enterpretif, digunakan untuk meneliti pada kondisi obyek yang alamiah, di mana peneliti adalah sebagai instumen kunci, teknik pengumpulan data dilakukan secara trianggulasi, data yang diperoleh cenderung data kualitatif, analisis data bersifat induktif/kualitatif, dan hasil penelitian kualitatif bersifat untuk memahami makna, memahami keunikan, mengkonstruksi fenomena, dan menemukan hipotesis (Sugiyono, 2018).

Teknik pengumpulan data Teknik Sampling Jenuh yaitu teknik penentuan sampel bila semua anggota populasi digunakan sebagai sampel. Metode pengumpulan data menggunakan metode Observasi dan Studi Pustaka. Metode observasi tak berperan dilakukan peneliti sebagai pengamat dengan mengamati rekaman video film Love for Sale 1 guna melihat tanda visual yang dapat dikaji. Observasi dilakukan cara mengamati tiaptiap adegan dalam film dari awal hingga akhir film, kemudian melakukan hasil pengamatan tiap adegan tersebut dibagi tiga babak sesuai dengan runtutan struktur ceritanya. Observasi dilakukan juga bertujuan untuk menemukan tipologi tokoh dan dimensi karakter pada tokoh Richard. Studi pustaka sebagai metode pengumpulan data dilakukan guna memperoleh data pendukung dan memperkuat temuan hasil observasi. Studi pustaka dilakukan pada berbagai literatur, baik majalah, resensi film, atau website resmi produsen film.

Miles and Huberman (dalam Sugiyono, 2018) mengemukakan bahwa aktivitas dalam analisis data kualitiatif dilakukan secara interaktif dan berlangsung secara terus menerus sampai tuntas, sehingga datanya sudah jenuh. Aktivitas dalam analisis data interaktif, yaitu data reduction (reduksi data), data display (sajian data) dan conclusion drawing/verification (penarikan kesimpulan dan verifikasi).

Reduksi data (data reduction) dilakukan dengan cara menyeleksi adeganadegan yang tokoh Richard sepanjang film untuk mencari dugaan maskulinitas yang tampak pada tokoh Richard dalam film. Tidak semua adegan dalam film memperlihatkan tindakan maskulin sehingga dibutuhkan observasi atau pengamatan tiap adegan dalam film untuk mereduksi data yang didapat untuk dikaji kemaskulinitasannya.

Sajian data (data display) menampilkan data yakni berupa adeganadegan Richard dalam film yang mengandung maskulinitas disertakan screenshot, timecode, dan deskripsi/ penjelasan adegan. Data yang sudah tersaji kemudian dikaji dengan landasan teori yang menjadi dasar penelitian ini, untuk kemudian ditentukan temuan penelitiannya, fokusnya pada jenis maskulinitas yang tergambar pada adegan dengan 


\section{CAPTURE}

menggunakan teori John Beynon

Penarikan kesimpulan (conclusion drawing) dilakukan terhadap sajian data. Lalu, kesimpulan diverifikasi dengan rumusan/tujuan masalah penelitian ini.

\section{PEMBAHASAN}

\subsection{Tokoh Richard}

Film Love for Sale 1 bercerita mengenai gambaran kehidupan sehari-hari seorang tokoh laki-laki bernama Richard yang masih melajang di usia 41 tahun. Richard diperankan oleh Gading Martin. Kehidupan Richard yang biasa saja (flat) setiap harinya, kemudian berubah saat Richard jatuh cinta kepada seorang wanita bernama Arini.

Tokoh Richard pada film Love for Sale 1 berfungsi sebagai tokoh utama dan memiliki peran sebagai tokoh protagonis. Richard merupakan anak angkat dari keluarga Wijaya yang tidak memiliki anak laki-laki. Kedua orang tua angkat Richard sudah lama wafat dan meninggalkan sebuah usaha percetakan bernama Prima Warna yang kemudian dilanjutkan oleh Richard.

Richard memiliki sifat yang tegas dan disiplin terhadap waktu. Richard yang masih betah menjalani kesehariannya seorang diri membuatnya sangat egosi dan kurang bersosialisasi dengan dunia luar.

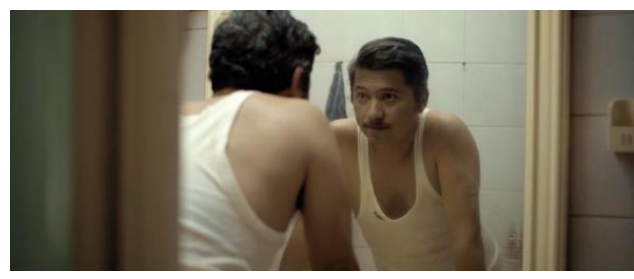

Gambar 1. Tokoh Richard yang sedang berkaca di kamar mandi rumahnya pagi hari. (Sumber: Film Love for Sale 1, 2018, TC: 00:00:45)

\subsection{Pengkarakteran Tokoh Richard}

\subsubsection{Tipologi Tokoh}

Tipologi tokoh dari karakter Richard dapat diidentifikasi sebagai berikut:

1) Tipologi Leptosom

Tipologi fisik tokoh Richard cenderung mengarah ke leptosom karena tubuhnya yang tinggi dan kurus. Tipe leptosom memiliki kegemaran menyendiri dan melamun. Hal tersebut dapat dilihat dari adegan Richard yang lebih menikmati hidup sendiri, kurang bersosialisasi dengan lingkungan luar, dan gemar melamun di depan kaca kamar mandi.

2) Tipologi Koleris

Sifat Richard yang tegas dan sering cepat marah kepada karyawannya karena melakukan kesalahan sepele, maka dapat dikategorikan memiliki tipologi psikis yaitu Koleris. Akan tetapi, Richard tidak menyimpan dendam kepada karyawannya. Richard tampak sibuk dan gemar memerintah karyawannya dibanding mengerjakan sendiri. Keinginan segala sesuatu harus dikerjakan dengan cepat mengejar keuntungan usahanya semakin menegaskan bahwa Richard sangat cocok dengan tipologi psikis Koleris. 


\subsubsection{Karakter 3D Tokoh Richard}

Karakter tiga dimensi dari tokoh Richard pada film Love for Sale 1 dapat dianalisis sebagai berikut:

\section{a) Fisiologis}

Tokoh Richard merupakan seorang laki-laki yang berusia 41 tahun dengan tinggi badan sekitar $175 \mathrm{~cm}$ dan berat badan sekitar 89 kg. Richard memiliki kulit cenderung putih, berambut hitam pendek dengan banyak uban putih yang mendominasi. Tokoh ini berhidung mancung, memiliki kumis, dan beralis mata tipis serta tampak garis kerutan di keningnya.

b) Sosiologis

Secara sosial, Richard hidup di keluarga yang mampu (berkecukupan). Hal itu ditunjukkan dengan peninggalan warisan berupa rumah berlantai dua yang berada di kompleks perumahan dan memiliki usaha percetakan. Richard merupakan anak sulung yang mempunyai dua orang adik. Richard jarang bersosialisasi dengan masyarakat sekitar rumahnya dan dunia luar. Richard lebih sering berinteraksi akrab dengan hewan peliharannya di rumah, menghabiskan waktu bersama temantemannya dan para karyawan di usaha percetakannya. Richard menyukai pertandingan sepak bola dengan temantemannya di sebuah bar sehingga Richard terkadang pulang larut pagi. Richard juga menyukai benda-benda berbau klasik dalam kehidupannya yang ditunjukkan dengan mobil klasik, piringan hitam, dan properti peninggalan sejarah yang ada di ruang tamu rumahnya.

c) Psikologis

Secara psikis, Richard merupakan seorang yang tegas, disiplin, suka memerintah orang lain, dan sering emosional terutama terhadap karyawannya. Selain itu, Richard memiliki sifat penyayang yang tampak pada adegan kesetiaannya merawat hewan peliharaan. Richard juga memiliki hasrat seksual yang tinggi untuk berhubungan badan di ranjang.

\subsection{Analisis Maskulinitas Tokoh Richard}

Analisis maskulinitas pada tokoh Richard pada film Love for Sale 1 diawali dengan pengamatan secara keseluruhan sekuan, adegan hingga shot. Untuk itu, peneliti membuat segmentasi sekuen, adegan, dan shot agar mempermudah dalam menganalisa data.

Pembagian sekuen yang dapat digunakan sebagai acuan dalam analisis maskulinitas pada karakter tokoh, sebagai berikut :

Tabel 2. Sekuen film Love for Sale 1

\begin{tabular}{|c|l|c|}
\hline No & \multicolumn{1}{|c|}{ Sekuen } & Timecode \\
\hline 1 & $\begin{array}{l}\text { Babak Pengenalan: } \\
\text { Pengenalan kehidupan } \\
\text { Richard dan teman- } \\
\text { temannya hingga } \\
\text { bertemu dengan tokoh } \\
\text { Arini }\end{array}$ & $\begin{array}{l}\text { 00:00:00- } \\
2\end{array}$ \\
$\begin{array}{l}\text { Babak Pertengahan: } \\
\text { Kehidupan dan } \\
\text { kebiasan Richard mulai } \\
\text { berubah semenjak } \\
\text { kehadiran Arini. }\end{array}$ & $\begin{array}{l}\text { 00:35:04- } \\
\text { 01:16:15 }\end{array}$ \\
\hline
\end{tabular}




\section{CAPTURE}

\begin{tabular}{|c|l|l|}
\hline & & \\
\hline 3 & $\begin{array}{l}\text { Babak Akhir (Klimaks): } \\
\text { Richard ditinggalkan } \\
\text { oleh Arini dan tingkah } \\
\text { laku Richard } \\
\text { sepenuhnya berubah. }\end{array}$ & \\
\hline
\end{tabular}

4.3.1 Analisis Data Sekuen 1

1) Adegan Richard di depan bar
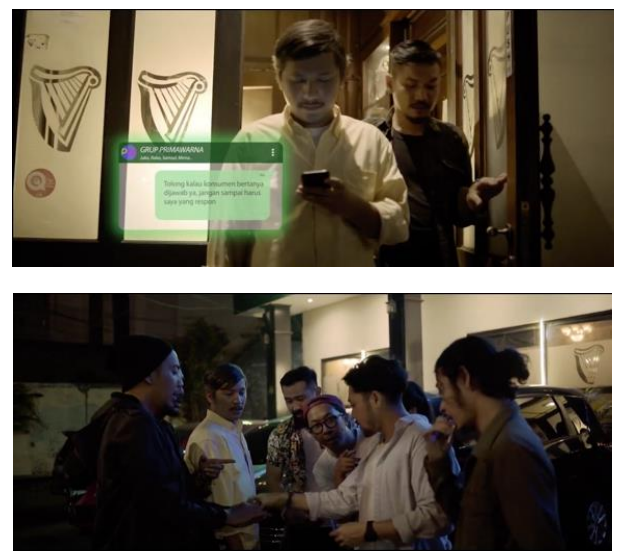

Gambar 2. Adegan Richard di depan sebuah Bar (Sumber: Film Love for Sale 1, 2018, TC: 00:03:5700:07:43)

Adegan ini menceritakan Richard dan teman-temannya berkumpul dan berbincang-bincang di depan sebuah bar seusai menonton bersama tayangan sepak bola di dalam bar tersebut. Richard merupakan sosok yang senang dengan olah raga terutama sepak bola. Kemudian teman-temannya menantang Richard untuk membawa pacarnya saat pesta pernikahan Rudy. Richard menerima tantangan itu demi mempertaruhkan harga dirinya.

Maskulinitas yang terlihat pada adegan ini bahwa kaum laki-laki khususnya Richard cenderung menyukai menonton bersama-sama pertandingan bola. Tempat bar digambarkan sebagai tempat untuk bersenang-senang para laki-laki untuk menghibur diri yang berbeda dengan kaum wanita yang cenderung pergi ke tempat perbelanjaan jika ingin menghibur diri. Lakilaki juga digambarkan sebagai sosok kompetitif dan berani mempertaruhkan harga diri, seperti digambarkan dalam adegan teman-teman Richard bertaruh sejumlah uang agar Richard membawa pacar saat pesta pernikahan Rudy. Richard pun menyanggupi dan terpaksa berbohong demi harga diri dan memenangkan pertaruhan itu. Hal ini Richard merupakan laki-laki maskulin kategori Status and Lifestyle.

2) Adegan Richard Berjalan pulang menuju rumahnya

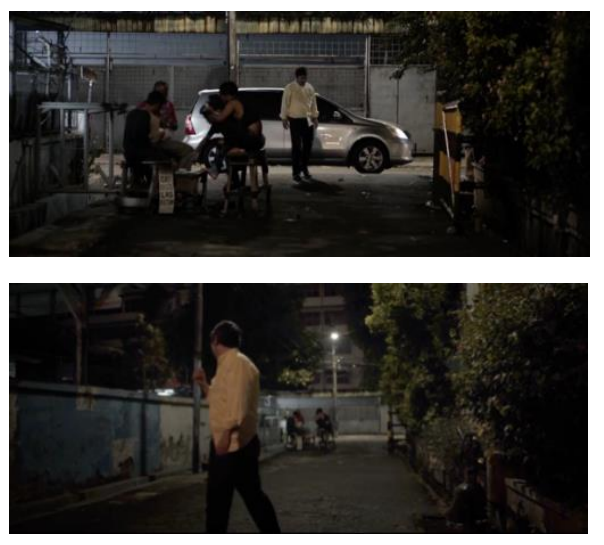

Gambar 3. Adegan Richard berjalan pulang. (Sumber: Film Love for Sale 1, 2018, TC: 00:08:12-00:08:36)

Adegan ini memperlihatkan Richard yang diantar pulang temannya dan turun di gang perumahan. Richard berjalan dan hanya menyapa sekelompok laki-laki paruh baya yang sedang duduk bermain kartu. Kemudian, Richard bertemu dengan satpam komplek perumahan, dan satpam memukulkan kentongan tiga kali ke tiang 
yang menunjukkan waktu pukul tiga pagi.

Maskulinitas Richard yang tampak adalah Richard merupakan seorang laki-laki yang sering begadang pulang larut pagi untuk menyaksikan pertandingan sepak bola. Konstruksi sosial yang dibentuk pada film ini adalah kebiasaan seorang laki-laki akan disebut maskulin apabila sering pulang larut atau begadang agar dicap pekerja keras. Masyarakat menganggap hal itu merupakan hal yang lazim untuk laki-laki karir pulang larut. Hal itu berbeda dengan kaum wanita yang cenderung tidak dapat pulang larut malam dan tentunya tanggapan masyarakat akan memandang negative pada kaum wanita yang suka pulang larut malam. Adegan ini menunjukkan Richard merupakan laki-laki maskulin kategori

\section{Culture and Subculture}

\section{3) Adegan Richard mengajak Danti berkencan}

Adegan ini menggambarkan Richard melihat Danti yang sedang membeli rujak di seberang jalan. Kemudian Richard mendatangi Danti dan mengajak Danti untuk ikut pergi menemaninya ke acara pernikahan Rudy.

Maskulinitas yang terlihat dalam adegan ini adalah Richard memberani diri untuk mengajak Danti pergi menemaninya ke pesta penikahan Rudy, padahal keduanya terpaut jauh. Konstruksi sosial yang dibentuk pada film ini bahwa kaum laki-laki khususnya Richard tampak agresif. Seorang laki-laki sepatutnya berani mengajak seorang wanita pergi berkencan. Hal itu dilakukan Richard agar berhasil memenangkan pertaruhan dengan temannya. Adegan ini memperlihatkan Richard sebagai laki-laki maskulin kategori Sexsual Orientation.

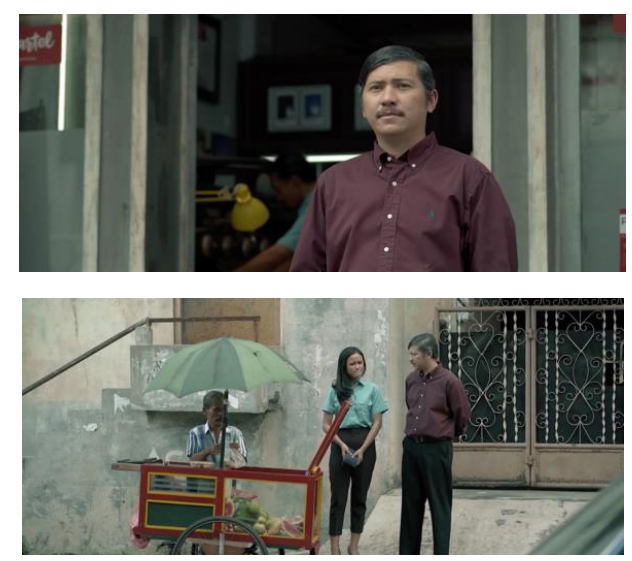

Gambar 4. Adegan Richard mengajak Danti berkencan.

(Sumber: Film Love for Sale 1, 2018, TC: 00:20:03$00: 21: 22)$

4) Adegan Richard bersama Arini datang di pesta pernikahan Rudy

Adegan ini memperlihatkan Richard berkemeja batik coklat yang sedang menghadiri pesta pernikahan Rudy dengan ditemani oleh Arini. Malam ini Richard tampil rapi, kemudian mendatangi temantemannya sambil bergandengan tangan dengan Arini. Richard mengenalkan Arini kepada teman-temannya sebagai pacarnya.

Maskulinitas yang tampak pada adegan ini adalah Richard yang berpakaian kemeja rapi sedang menggandeng Arini dan memperkenalkannya kepada teman-teman di sebuah acara pernikahan. Konstruksi sosial laki-laki yang tergambar pada adegan ini bahwa laki-laki terlihat gentle dan 


\section{CAPTURE}

maskulin, apabila membawa pasangannya di pesta pernikahan teman. Adegan ini menunjukkan Richard merupakan laki-laki maskulin kategori Sexsual Orientation.
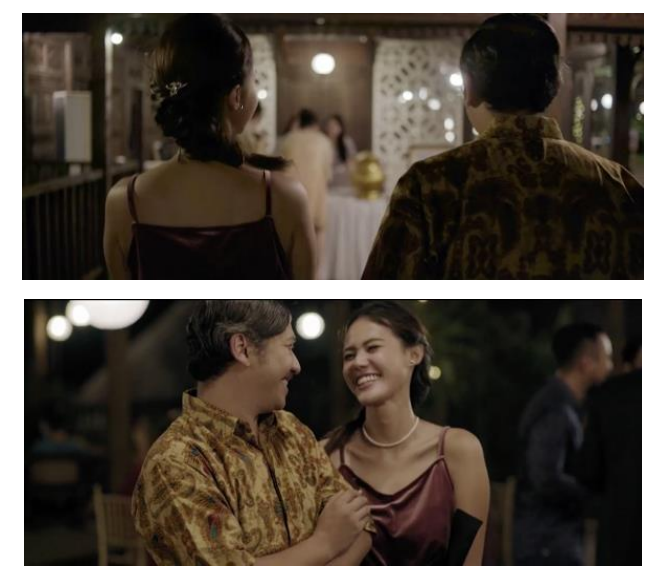

Gambar 5. Adegan Richard bersama Arini di pesta pernikahan Rudy

(Sumber: Film Love for Sale 1, 2018, TC: 00:33:3700:35:03)

\subsubsection{Analisis Data Sekuen 2}

1) Adegan Richard jalan berdua dengan Arini

Adegan ini menggambarkan Richard yang sedang jalan berdua di pinggir jalan raya yang ramai pada malam hari di Jakarta. Richard dan Arini jalan bergandengan tangan dengan mesranya, dan kemudian Richard memutuskan untuk menggendong Arini di punggungnya.

Maskulinitas yang tampak pada adegan ini yaitu Richard sanggup menggendong Arini dan melanjutkan jalanjalan menikmati keindahan malam hari. Konstruksi sosial yang tergambar bahwa kaum lak-laki cenderung memiliki fisik lebih kuat dan menampilkan kekuatannya di depan kaum wanita. Hal itu menggambarkan bahwa laki-laki lebih perkasa dan dinilai sebagai sifat dari maskulin. Maka dari itu, adegan Richard ini menunjukkannya sebagai laki-laki maskulin kategori Sexsual Orientation.
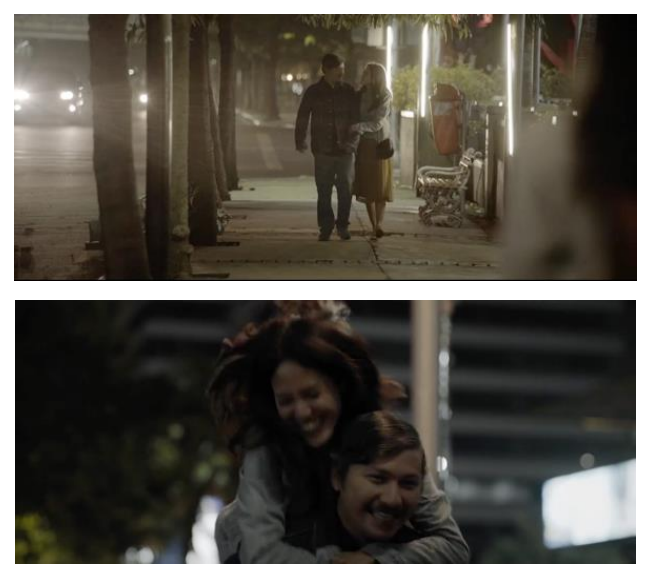

Gambar 6. Adegan Richard jalan berdua dengan Arini pada malam hari

(Sumber: Film Love for Sale 1, 2018, TC: 00:56:1000:57:00)

2) Adegan Richard mengatasi masalah pada pelanggannya

Adegan ini tampak Richard datang ke kantornya malam hari, kemudian mengatasi permasalahan pelanggannya yang komplain salah bahan kertas. Richard mengambil keputusan untuk mengganti semua pesanan yang salah dalam waktu tiga hari. Jaka, Raka, dan Pak Syamsul menuruti keputusan Richard.

Maskulinitas pada adegan ini terlihat bahwa Richard sebagai pemimpin dari usaha percetakannya tampak tegas dalam mengambil keputusan, bertanggung jawab dan mendominasi dibanding Jaka, Raka dan Pak Syamsul. Mereka bertiga menuruti keputusan Richard. Konstruksi sosial laki-laki yang terbangun yaitu laki-laki maskulin adalah laki-laki yang 
mendominasi, tidak lembek, bertanggung jawab, dan tegas. Adegan ini Richard menunjukkan laki-laki maskulin kategori Class and Occupation.
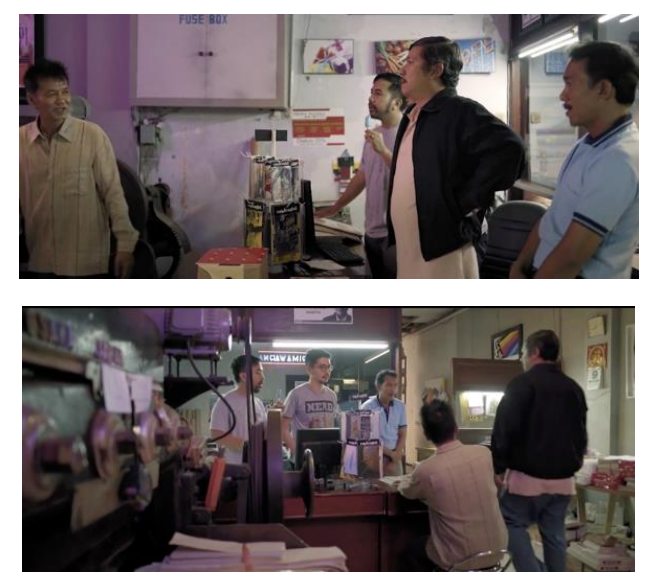

Gambar 7. Adegan Richard mengatasi permasalahan pelanggannya di kantor

(Sumber: Film Love for Sale 1, 2018, TC: 01:01:5601:02:51)

\section{3) Adegan Richard menjemput Arini}
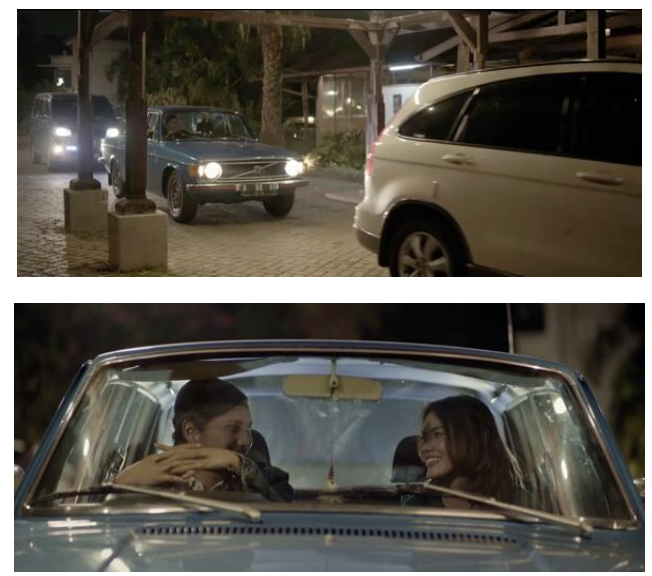

Gambar 8. Adegan Richard menjemput Arini dengan mobilnya.

(Sumber: Film Love for Sale 1, 2018, TC: 01:04:4701:05:07)

Adegan ini berisi Richard yang menjemput Arini dengan mobil klasiknya selepas melihat konser piano klasik pada malam hari.

Maskulinitas pada adegan ini tampak tokoh Richard menjemput Arini untuk pulang bersama-sama. Konstruksi sosial yang tergambar pada film bahwa laki-laki maskulin adalah laki-laki yang romantic, bersedia mengantar, dan menjemput kaum wanita. Adegan ini menunjukkan Richard sebagai laki-laki maskulin kategori Sexsual Orientation.

4) Adegan Richard memberikan uang kepada anak kecil
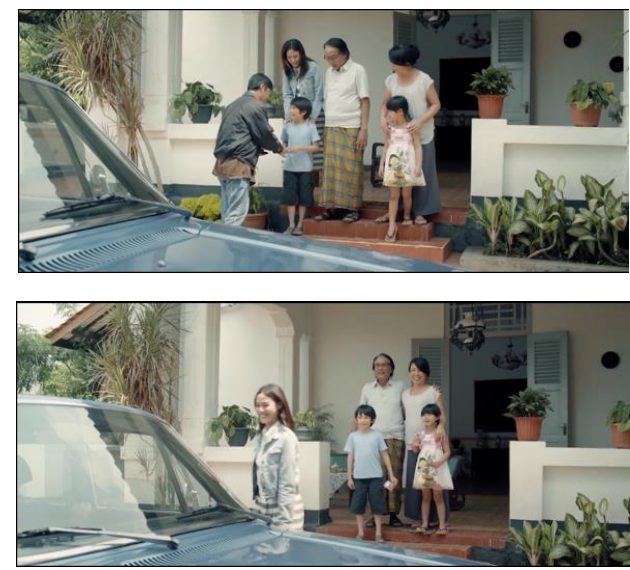

Gambar 9. Adegan Arini membawakan makan untuk Richard di kantor

(Sumber: Film Love for Sale 1, 2018, TC: 01:09:3901:09:57)

Adegan ini menggambarkan Richard sedang memberikan sejumlah uang kepada anak kecil, adiknya Arini. Kemudian, Richard dan Arini berpamitan pulang kembali ke Jakarta.

Maskulinitas pada adegan ini adalah saat Richard memberikan sejumlah uang kepada anak kecil yang dikenalkan kepada Richard sebagai adik Arini. Konstruksi sosial yang tergambar pada adegan ini yaitu laki-laki maskulin adalah laki-laki yang mapan dan memiliki dominasi yang lebih dibanding wanita dari segi karir atau harta. Laki-laki mapan sepatutnya 


\section{CAPTURE}

memberikan sesuatu pada wanita atau anak-anak. Adegan ini tampak Richard merupakan laki-laki maskulin kategori Class and Occupation.

5) Adegan Richard bekerja di kantor dan Arini membawakan makanan
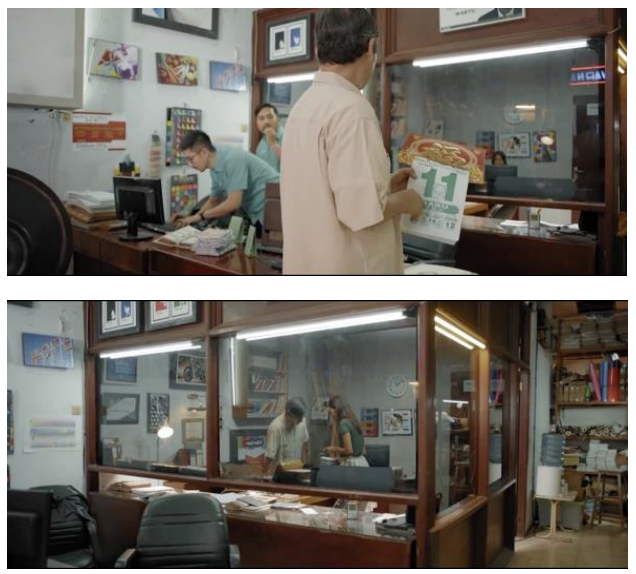

Gambar 10. Adegan Arini membawakan makan untuk Richard di kantor

(Sumber: Film Love for Sale 1, 2018, TC: 01:09:58$01: 11: 42)$

Adegan ini berisi Richard yang datang ke kantor untuk bekerja kemudian tiba-tiba Arini datang dengan membawa rantang untuk makan siang Richard. Richard kemudian mencium kening Airini dan menyuruh karyawannya untuk istirahat makan siang.

Maskulinitas yang terdapat pada adegan ini adalah Richard seorang perkerja keras dalam melanjutkan bisnis percetakannya. Konstruksi sosial yang terbentuk pada adegan ini bahwa kaum lakilaki sejak lahir hingga dewasa dibebankan peran untuk bekerja keras. Maskulinitas akan terlihat apabila kaum laki-laki bekerja keras atau membanting tulang untuk menafkahi keluarganya. Adegan ini tampak Richard merupakan laki-laki maskulin kategori Class and Occupation.

6) Adegan Richard memberikan kejutan cincin untuk Arini
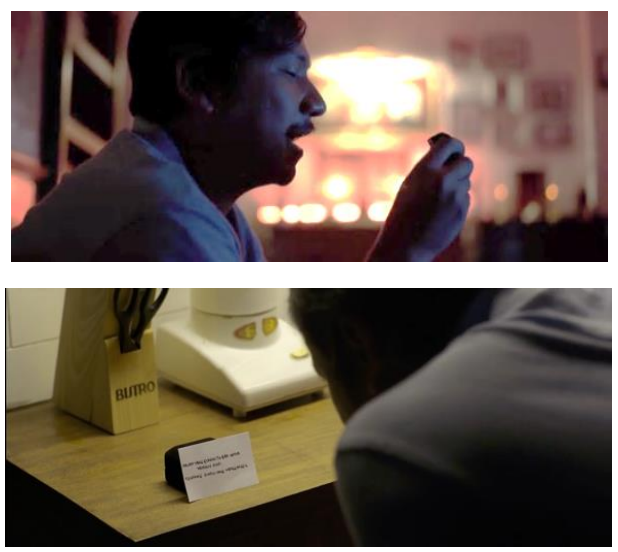

Gambar 11. Adegan Richard memberikan kejutan untuk Arini

(Sumber: Film Love for Sale 1, 2018, TC: 01:15:2501:16:02)

Adegan ini menunjukkan bahwa Richard akan memberi kejutan kepada Arini dengan sebuah cincin dan secarik kertas kecil yang berisikan kalimat romantis. Kemudian Richard meletakkan cincin dan secarik kertas itu di atas meja.

Maskulinitas yang tergambar pada adegan ini adalah Richard juga sosok penyayang dan romantis. Konstruksi sosial yang terbentuk dari adegan ini bahwa lakilaki maskulin adalah laki-laki yang romantis. Laki-laki yang suka memberikan kejutan untuk menunjukkkan rasa sayang dan tanggung jawabnya. Laki-laki cenderung harus rela berkorban untuk kaum wanita. Adegan ini tampak Richard sebagai laki-laki maskulin kategori Class and Occupation. 


\subsubsection{Analisis Data Sekuen 3}

1) Adegan Richard meminum bir di ruang tamu
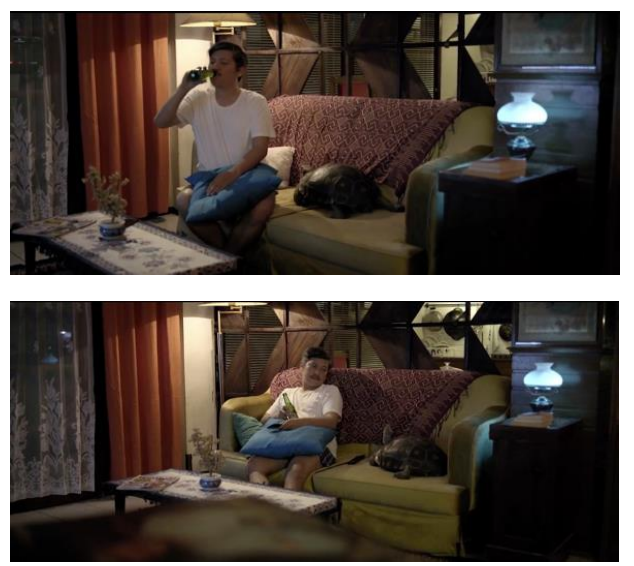

Gambar 12. Adegan Richard meminum bir sambil bercengkarama dengan hewan peliharaannya (Sumber: Film Love for Sale 1, 2018, TC: 01:21:40$01: 22: 26)$

Adegan ini menunjukkan Richard duduk di sofa ruang tamu rumahnya menonton televisi, meminum sebotol bir, dan sambil bercengkaram dengan kura-kura peliharaan di sampingnya. Kemudian Richard mencoba lagi menghubungi nomer ponsel Arini, tetapi masih tetap tidak aktif.

Maskulinitas yang terlihat dalam adegan ini yaitu Richard meminum sebotol bir melepas lelah usai mencari Arini tapi tetap tidak ada kabar. Richard meminum bir tersebut bertujuan untuk menenangkan diri. Hal itu biasa dilakukan oleh kaum laki-laki, apabila mengalami stres atau frustasi. Kontruksi sosial yang terbentuk bahwa lakilaki cenderung meminum bir atau minuman keras di kala lelah, sedih atau stres untuk sekedar menenangkan diri atau menghibur, dan tidak dengan menangis. Adegan ini mencerminkan Richard merupakan laki-laki maskulin kategori Status and Lifestyle.

\section{2) Adegan Richard berpamitan dan pergi menggunakan motor barunya.}
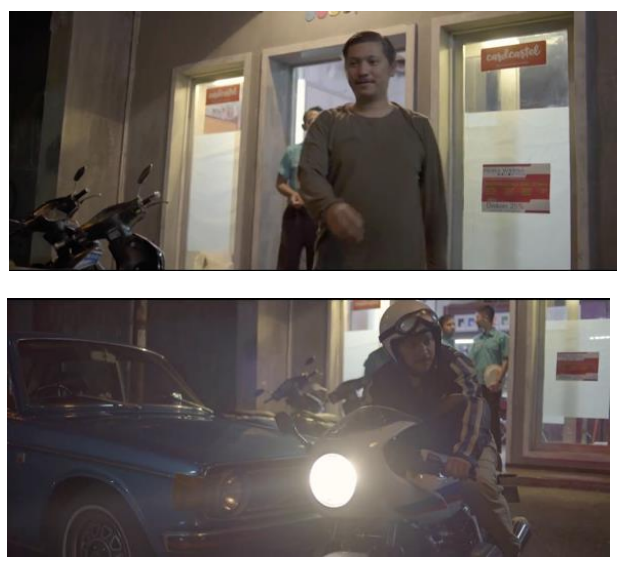

Gambar 13. Adegan Richard pergi meninggalkan rumahnya menggunakan sepeda motor barunya. (Sumber: Film Love for Sale 1, 2018, TC: 01:35:3901:36:25)

Adegan ini menunjukkan Richard memberikan mobil klasiknya ke Pak Syamsul, kemudian berpamitan pergi dengan Jaka, Raka, dan Pak Syamsul menggunakan motor bermerk BWM barunya dengan jaket dan helm layaknya seorang anggota komunitas motor. Adegan ini tampak Richard memutuskan pergi dengan menggunakan motor barunya bertujuan untuk mencoba membuka dir, karena sebelumnya Richard sangat sukar untuk bersosialisasi dengan dunia luar.

Maskulinitas yang terlihat dalam adegan ini adalah bahwa Richard memilih untuk memberikan mobil klasiknya dan pergi menggunakan motor barunya yang bermerek BMW. Konstruksi sosial yang terbangun dalam adegan ini bahwa laki-laki akan terlihat maskulin, apabila pergi 


\section{CAPTIRE}

mengendarai motor terutama motor yang bermerek. Hal itu tampaknya disengaja oleh sutradara agar tokoh Richard terlihat lebih macho dan gagah dibanding dengan pergi menggunakan mobil klasiknya. Adegan ini tampak Richard merupakan laki-laki maskulin kategori Status and Lifestyle.

\section{SIMPULAN}

Hasil penelitian mengenai analisis maskulinitas karakter Richard dalam film Love for Sale 1 menunjukkan bahwa konstruksi sosial laki-laki yang dibangun dalam film Love for Sale 1 merupakan perwakilan dari gambaran konstruksi sosial yang ada di kehidupan nyata. Adanya kesamaan konstruksi sosial maskulinitas antara tokoh Richard dalam film Love for Sale 1 dengan di kehidupan nyata.

Maskulinitas yang terbentuk dari tokoh Richard dapat dinilai dari beberapa hal yaitu: 1) gaya hidupnya yang senang pergi ke bar untuk menghibur diri dan menonton bola; 2) kebiasaan begadang hingga larut pagi; 3) ketegasannya dalam memimpin dan mengambil keputusan; 4) kisah asmaranya dan perlakuan romantisnya terhadap Arini; dan 5) kelangsungan usaha percetakan menandakan karir dan harta Richard yang mapan.

\section{DAFTAR ACUAN}

Bourdieu, P. (2010). Dominasi Maskulin. Jalasutra.

Lutters, E. (2004). Kunci Sukses Menulis Skenario. Grasindo.
Mecca, A. (2019). Photo Selfie as Women's Expression of Femininity. CAPTURE: Jurnal Seni Media Rekam, 10(2), 1-19. https://doi.org/10.33153/capture.v1 $0 \mathrm{i} 2.2246$

Pramudika, A. D. (2015). Visualisasi Maskulinitas melalui Pengkarakteran Tokoh dalam Film $5 \mathrm{~cm}$ [Skripsi tidak diterbitkan]. ISI Surakarta.

Pratista, H. (2008). Memahami Film. Homerian Pustaka.

Sobur, A. (2009). Semiotika Komunikasi. Remaja Rosdakarya.

Sugiyono. (2018). Metode Penelitian Kualitatif. Alfabeta.

Syulhajji S. (2017). Representasi Maskulinitas dalam Film Talak 3 (Studi Analisis Semiotika Roland Barthes). EJournal IImu Komunikasi, 5(3), 01-11.

Wulan Sari, K., \& Haryono, G. (2018). Hegemoni Budaya Patriarki pada Film. Jurnal Semiotika, 12(1), 59. 